\title{
Erratum to: Exogenous spatial attention decreases audiovisual integration
}

\author{
N. Van der Stoep • S. Van der Stigchel • T. C. W. Nijboer
}

Published online: 25 November 2014

(C) The Psychonomic Society, Inc. 2014

Erratum to: Attention, Perception, \& Psychophysics

DOI 10.3758/s13414-014-0785-1

Due to an error in the publication process the race model formula was displayed incorrectly as:

$$
\begin{aligned}
\operatorname{array} P\left(R T_{\text {Race Model }}<t\right)= & P\left(R T_{A}<t\right)+P\left(R T_{V}<t\right) \\
& -P\left(R T_{A}<t\right) \times P\left(R T_{V}<t\right)
\end{aligned}
$$

The correct formula is:

$$
\begin{aligned}
P\left(R T_{\text {Race Model }}<t\right)= & P\left(R T_{A}<t\right)+P\left(R T_{V}<t\right) \\
& -P\left(R T_{A}<t\right) \times P\left(R T_{V}<t\right)
\end{aligned}
$$

The online version of the original article can be found at http://dx.doi.org/ 10.3758/s13414-014-0785-1.

N. Van der Stoep $(\varangle) \cdot$ S. Van der Stigchel $\cdot$ T. C. W. Nijboer Department of Experimental Psychology, Helmholtz Institute, Utrecht University, Heidelberglaan 2, 3584 CS Utrecht,

The Netherlands

e-mail: n.vanderstoep@uu.nl

T. C. W. Nijboer

Brain Center Rudolf Magnus, and Center of Excellence for

Rehabilitation Medicine, University Medical Center Utrecht and De

Hoogstraat Rehabilitation, Utrecht, The Netherlands 